Case Report

\title{
Adenomatoid Tumor of the Tunica Albuginea in a Boy: A Case Report and Literature Review
}

\author{
Kaimin Guo, ${ }^{1}$ Runhui Tian, ${ }^{2}$ Lingyun Liu, ${ }^{1}$ Congqi Du, ${ }^{1}$ Fubiao Li, ${ }^{1}$ and Hongliang Wang ${ }^{1}$ \\ ${ }^{1}$ Department of Andrology, First Hospital of Jilin University, Changchun, Jilin 130021, China \\ ${ }^{2}$ Department of Psychology, First Hospital of Jilin University, Changchun, Jilin 130021, China \\ Correspondence should be addressed to Hongliang Wang; criston@163.com
}

Received 22 March 2015; Accepted 14 May 2015

Academic Editor: Pilar González-Peramato

Copyright (C) 2015 Kaimin Guo et al. This is an open access article distributed under the Creative Commons Attribution License, which permits unrestricted use, distribution, and reproduction in any medium, provided the original work is properly cited.

\begin{abstract}
Adenomatoid tumors (AT) are the most common paratesticular neoplasms and account for approximately $30 \%$ of all paratesticular masses. Most of them occur in the third or fourth decade and present as well-defined firm and painless masses. We report here a case of adenomatoid tumor from tunica albuginea. This patient is a 12-year-old boy with left testicular pain for 6 months. Scrotal ultrasonography revealed a solid mass of paratesticular origin. The histology and immunohistochemistry confirmed the final diagnosis. A right tumor resection was performed. Because of its rarity, the clinical and histopathologic appearance is seldom illustrated. Here we present a case report and a comprehensive literature review with the objective of providing useful information on this entity.
\end{abstract}

\section{Introduction}

Adenomatoid tumors (AT) are benign tumors most commonly occurring in the male and female genital tracts. Extragenital AT are rare and have been found in the adrenal glands, heart, mesentery, lymph nodes, and pleura [1]. When the mass arises from the tunica vaginalis or tunica albuginea, sonographic findings may distinguish it from a peripheral testicular tumor [2]. The structural growth pattern is atypical of benign neoplasms, as they are generally not encapsulated, and tumor elements are commonly present between the structures of adjacent tissues and may show clear-cut infiltration [3]. Considering most intratesticular tumors are malignant, we report a rare case and management of an AT originating from tunica albuginea.

\section{Case Report}

A 12-year-old boy presented to the andrology department in June 2013 with left testicular pain that he had had for 6 months. There was no history of recent trauma, infection, hydrocele, or undescended testis. He denied having any urinary or constitutional symptoms. Physical examination revealed a hard, tender, $10 \mathrm{~mm} \times 10 \mathrm{~mm} \times 8 \mathrm{~mm}$ testicular nodule in the superior aspect of the left testis. The contralateral testicle was normal.

Scrotal ultrasonography (8 to 12 linear array transducer, LOGIQ P5, GE Healthcare, New York, New York State, USA) revealed $8 \mathrm{~mm} \times 10 \mathrm{~mm}$, hypoechoic homogeneous solid mass with unclear margin at the junction of the epididymis and left testis (Figure 1). Serum tumor markers, including alpha-fetoprotein, beta-human chorionic gonadotropin, and lactate dehydrogenase, were all within normal limits. All preoperative laboratory tests, including complete blood count, biochemistry, and chest X-ray, were normal. A pelvic computerized tomography (CT) scan was negative for retroperitoneal metastasis. The provisional diagnosis was paratesticular tumor, with the possibility of benign nature.

The patient was then referred to our institution for surgical treatment. The left inguinal approach was established and the left spermatic cord was identified. On visual inspection, the tumor arose from the tunica albuginea protruding into the testis parenchyma. Intraoperative frozen-section biopsy showed benign tumor from tunica albuginea. Subsequently, a right tumor resection including removing a portion of tunica albuginea was performed. 
TABLE 1: Characteristics and clinical course of published cases of AT from tunica albuginea.

\begin{tabular}{|c|c|c|c|c|c|c|}
\hline \multicolumn{2}{|c|}{ Case number Age } & \multirow{2}{*}{$\begin{array}{c}\text { Symptom and duration } \\
\text { Dull pain of right scrotum } \\
\text { for } 1 \text { year }\end{array}$} & Location & Size & Treatment & \multirow{2}{*}{$\begin{array}{c}\text { Past history } \\
\text { Previous } \\
\text { seminoma by } \\
\text { FNA }\end{array}$} \\
\hline $1[7]$ & 40 & & The lower pole of the RT & $4 \times 3.5 \mathrm{~cm}$ & $\mathrm{RO}$ & \\
\hline $2[9]$ & 40 & $\begin{array}{l}\text { A painless, rapidly growing } \\
\text { mass for } 1 \text { year }\end{array}$ & The lower pole of the RT & $5 \mathrm{~cm}$ & RO & Negative \\
\hline $3[10]$ & 45 & $\begin{array}{l}\text { A painless palpable mass } \\
\text { for } 1 \text { month }\end{array}$ & Anterior surface of RT & $0.5 \times 0.7 \mathrm{~cm}$ & Tumor resection & Negative \\
\hline $4[11]$ & 27 & $\begin{array}{c}\text { A painless palpable mass of } \\
\text { left scrotum }\end{array}$ & The lower pole of the LT & $1.0 \mathrm{~cm}$ & Partial orchiectomy & Negative \\
\hline $5[12]$ & 36 & $\begin{array}{l}\text { A painless palpable mass } \\
\text { for } 2 \text { months }\end{array}$ & The lower pole of the RT & $0.8 \times 0.7 \mathrm{~cm}$ & RO & $\begin{array}{l}\text { Pulmonary } \\
\text { tuberculosis }\end{array}$ \\
\hline $6[14]$ & 40 & $\begin{array}{l}\text { A painless palpable mass } \\
\text { for } 1 \text { year }\end{array}$ & The lower pole of the RT & $4 \times 3 \mathrm{~cm}$ & $\mathrm{RO}$ & Negative \\
\hline $7[15]$ & 44 & $\begin{array}{l}\text { A painless palpable mass } \\
\text { for } 1 \text { year, enlarging for } 3 \\
\text { months }\end{array}$ & Midposterior aspect of the RT & $0.7 \times 0.6 \times 0.5 \mathrm{~cm}$ & $\mathrm{RO}$ & Negative \\
\hline Our case & 12 & Left testicular pain & Upper pole of the LT & $0.8 \times 1.0 \mathrm{~cm}$ & Tumor resection & Negative \\
\hline
\end{tabular}

RT: right testis; LT: left testis; FNA: fine needle aspiration. RO: radical orchiectomy.

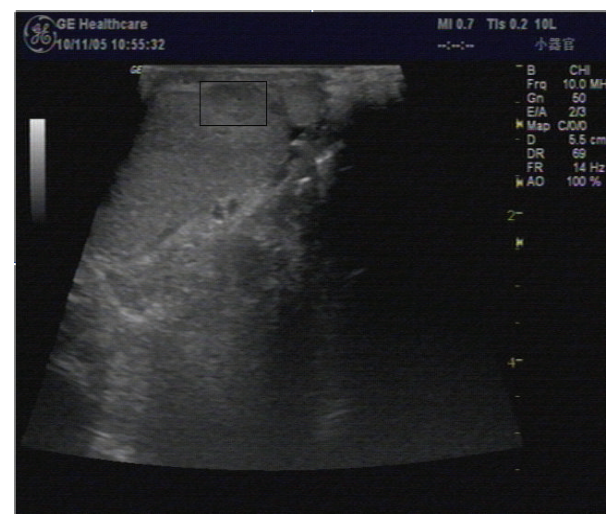

FIGURE 1: Scrotal ultrasonography of AT: scrotal ultrasound scan revealing a $10 \times 8 \mathrm{~mm}$, hyperechoic solid mass in the upper pole of the left testicle.

Final histological examination confirmed the diagnosis of AT from the tunica albuginea (Figure 2). Immunohistochemical analysis revealed the tumor cells were positive for calretinin, cytokeratin, and vimentin (Figure 3 ). The postoperative course was uneventful. After 12 months of follow-up, the patient was asymptomatic without any evidence of local recurrence.

\section{Discussion}

AT are the most common paratesticular neoplasms and account for approximately $30 \%$ of all paratesticular masses [4]. It was firstly described by Golden and Ash in 1945 [5]. The epididymis is the most common site of involvement. The origin from the testicular tunica is estimated $14 \%$ of AT [6]. We searched relevant case reports published in English that were available in full-text and found only 7 related cases (Table 1).
In our review, AT from tunica albuginea usually occur in the third or fourth decade and present as well-defined firm, painless masses that have been noted for several months to 1 year or discovered incidentally on physical examination. Most of them are asymptomatic and only two patients complain of dull pain of testis or scrotal discomfort [7]. Rightsided tunica albuginea is easily involved (right/left: 6/2), and lower pole of testis is commonly located. They are usually small in size rarely exceeding $5 \mathrm{cmm}$ (range is $0.5-5.0 \mathrm{~cm}$ ). The origin of this tumor is unknown, but some are considered to be a reaction to either injury or inflammation, and others are thought to be of mesothelial origin [8]. 7 cases of AT from tunica albuginea had no history of scrotal trauma or testis infection except one case reported pulmonary tuberculosis. We conclude the occurrence and progression of AT from tunica albuginea have no relationship with past injury and inflammation.

Ultrasound of the scrotum reveals a well-defined interface between the tunical mass and the displaced testicular parenchyma [9]. Kolgesiz et al. described a maneuver that radiologists examine the mass and the testis on a sagittal view with the ultrasonic probe in one hand, while pushing the testis downward with the other hand which could facilitate differentiating the mass as being extratesticular in location [10]. Magnetic resonance imaging (MRI) allows characterization of scrotal masses as being intratesticular or extratesticular and can demonstrate various types of lesions and tissue, including cysts or fluid, solid masses, fat, and fibrosis [11]. The depiction of the thin low-signal well-delineated zone between the mass and the adjacent testicular parenchyma, corresponding to the tunica albuginea, helped to indicate the origin of the mass [12]. In our case, a hypoechoic, homogeneous, solid mass with unclear margin adjacent to the tunica albuginea was noted by ultrasonography. So the preoperative diagnosis of testicular tumor was established. 


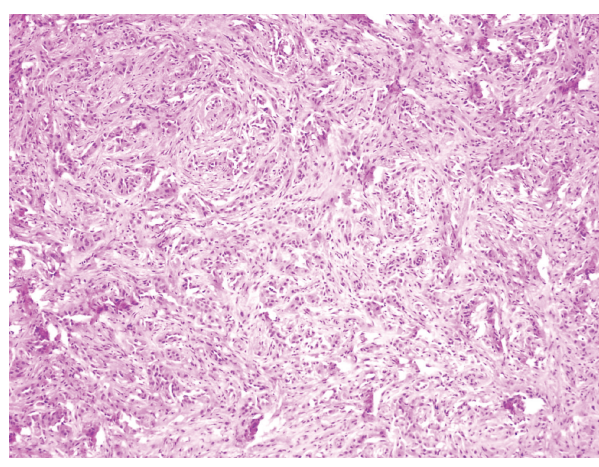

(a)

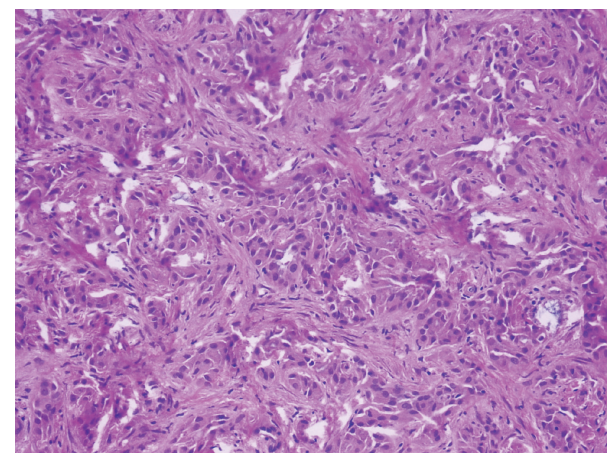

(b)

FIGURE 2: HE staining of AT: (a) hematoxylin-eosin stain of tumor biopsy showing tumor cells lined in irregular, glandular pattern, and fibrous tissue proliferation in stroma with unclear margins $(\times 100)$; (b) the neoplastic cells had round to polygonal outlines, moderate to abundant pale to vacuolated cytoplasm with round or oval nuclei. No mitoses were seen (hematoxylin-eosin, $\times 200)$.

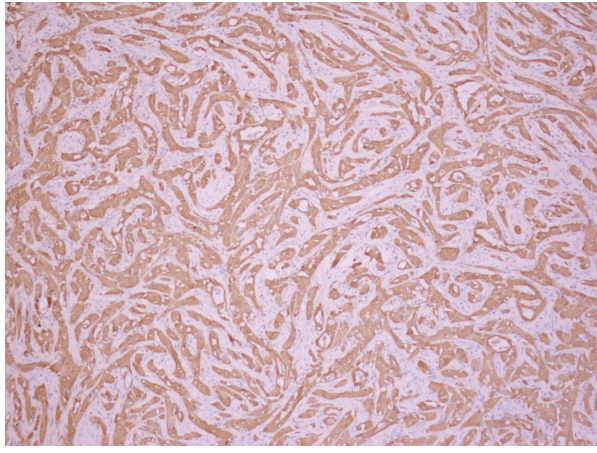

(a)

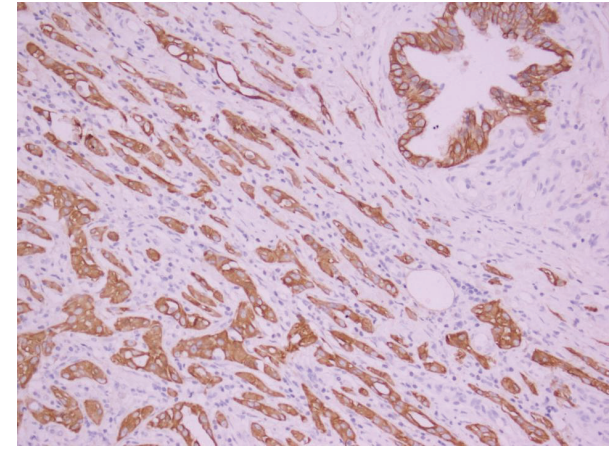

(b)

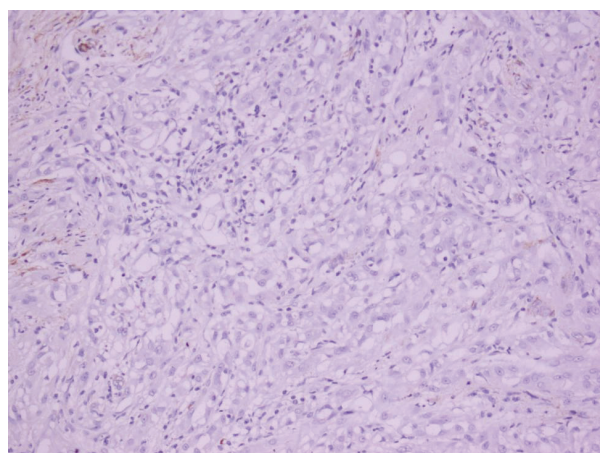

(c)

FIGURE 3: Immunostaining of adenomatoid tumors. (a) Calretinin (+); (b) cytokeratin (+); (c) vimentin (+) $(\times 200)$.

The imprint cytology and fine needle aspiration cytology (FNAC) have been applied to confirm the diagnosis [12]. Microscopically they have two major elements: epithelial-like cells and a fibrous stroma. Epithelial cell arrangement allows for recognizing three patterns: plexiform, glandular, and angiomatoid. Stroma may consist of loose or dense collagen tissue with hyalinization and is found in variable amounts. The cytological origin of the AT is controversial and the cells are cytokeratin 5/6, calretinin, and vimentin positive, as we could show in the present case report, and epithelial markers of factors VIII and CD34 negative [13], indicating the mesothelial nature of the lesion. Thus, cytokeratin 5/6 and calretinin are useful to distinguish between mesothelial tumor and seminoma.

Orchiectomy has traditionally been the gold standard for the treatment of testicular tumors in children. Tumor resection appears to be the treatment of choice only when a benign lesion confirmed. But in our review, we found only one case underwent partial orchiectomy and one case performed tumor resection. The rest of cases underwent orchiectomy. Both Garg and Monappa established the diagnosis of seminoma preoperatively by FNAC [7, 14], while Barry, Lee, and Evans described cases with ill-defined lesions and unclear borders between masses and the testis, which made the 
malignancy not be excluded $[9,12,15]$. In our present case, even if the tumor demonstrated unclear border with testis in ultrasonography and protruded into the testis parenchyma in operation, the testis and the epididymis were not involved. After consulting with an experienced pathologist intraoperatively and preserving the patient's fertility potential, removing the tumor with clear margin and suturing the tunica albuginea were considered. AT have not been known to ever recur or show malignant degeneration. According to literature, no cases of malignization, metastasis, or relapse after removal have been reported.

\section{Conclusions}

This case highlights the difficulty of accurately diagnosing a paratesticular mass preoperatively when the origin of the mass cannot be established before excision. We report this case for its rarity of origin and occurrence in a young boy. So this benign tumor should be borne in mind and testis should be spared as possible as we can.

\section{Abbreviations}

AT: $\quad$ Adenomatoid tumors

FNAC: Fine needle aspiration cytology

RT: Right testis

LT: $\quad$ Left testis

RO: Radical orchiectomy.

\section{Consent}

Written informed consent was obtained from the patient for publication of this case report and any accompanying images.

\section{Conflict of Interests}

The authors declare that they have no competing interests.

\section{Authors' Contribution}

Kaimin Guo wrote the initial draft. Hongliang Wang conceived of the study design, Runhui Tian, Lingyun Liu, and Congqi Du collected relevant literatures and modified the draft, and Hongliang Wang and Fubiao Li performed the operation. All authors read and approved the final paper.

\section{Acknowledgments}

The authors are indebted to Professor Meishang Jing, Department of Pathology, the First Hospital of Jilin University, for providing valuable pathology support.

\section{References}

[1] P. A. Isotalo, G. L. Keeney, T. J. Sebo, D. L. Riehle, and J. C. Cheville, "Adenomatoid tumor of the adrenal gland: a clinicopathologic study of five cases and review of the literature," American Journal of Surgical Pathology, vol. 27, no. 7, pp. 969977, 2003.
[2] A. Ihsan Kolgesiz, F. Kantarci, A. Kadioglu, and I. Mihmanli, "Adenomatoid tumor of the tunica vaginalis testis: a special maneuver in diagnosis by ultrasonography," Journal of Ultrasound in Medicine, vol. 22, no. 3, pp. 303-305, 2003.

[3] T. L. J. Tammela, T. J. Karttunen, H. P. Mäkäräinen, P. A. Hellström, S. I. Mattila, and M. J. Kontturi, "Intrascrotal adenomatoid tumors," Journal of Urology, vol. 146, no. 1, pp. 61-65, 1991.

[4] B. Delahunt, J. N. Eble, D. King, P. B. Bethwaite, J. N. Nacey, and A. Thornton, "Immunohistochemical evidence for mesothelial origin of paratesticular adenomatoid tumour," Histopathology, vol. 36, no. 2, pp. 109-115, 2000.

[5] A. Golden and J. E. Ash, "Adenomatoid tumors of the genital tract," The American Journal of Pathology, vol. 21, no. 1, pp. 6379, 1945.

[6] D. P. de Klerk and F. Nime, "Adenomatoid tumors (mesothelioma) of testicular and paratesticular tissue," Urology, vol. 6, no. 5, pp. 635-641, 1975.

[7] S. Garg, M. Mathew, J. Thomas, and T. Goel, "Adenomatoid tumor of Tunica albuginea mimicking a testicular neoplasm," The Internet Journal of Urology, vol. 4, no. 2, 2006.

[8] J. P. Richie, "Neoplasms of the testis," in Campbell's Urology, P. C. Walsh, A. B. Retik, E. D. Vaughan et al., Eds., vol. 3, pp. 24442446, WB Saunders, Philadelphia, Pa, USA, 7th edition, 1998.

[9] K. Evans, "Rapidly growing adenomatoid tumor extending into testicular parenchyma mimics testicular carcinoma," Urology, vol. 64, no. 3, p. 589, 2004.

[10] A. I. Kolgesiz, F. Kantarci, A. Kadioglu, and I. Mihmanli, "Adenomatoid tumor of the tunica vaginalis testis: a special maneuver in diagnosis by ultrasonography," Journal of Ultrasound in Medicine, vol. 22, no. 3, pp. 303-305, 2003.

[11] M. D. Patel and A. C. Silva, "MRI of an adenomatoid tumor of the tunica albuginea," American Journal of Roentgenology, vol. 182, no. 2, pp. 415-417, 2004.

[12] J. I. Lee, "Touch imprint cytology of adenomatoid tumor of the tunica albuginea: a case report," The Korean Journal of Cytopathology, vol. 19, no. 1, pp. 47-51, 2008.

[13] M. Á. Maestro, R. T. González, J. M. A. Dorrego, J. de La Peña Barthel, and M. N. M. De Serrano, "Adenomatoid tumors of the epididymis and testicle: report of 9 cases and bibliographic review," Archivos Espanoles de Urologia, vol. 62, no. 2, pp. 137141, 2009.

[14] V. Monappa, A. C. K. Rao, G. Krishnanand, M. Mathew, and S. Garg, "Adenomatoid tumor of tunica albuginea mimicking seminoma on fine needle aspiration cytology: a case report," Acta Cytologica, vol. 53, no. 3, pp. 349-352, 2009.

[15] P. I. Barry, K. G. Chan, J. Hsu, and M. L. Quek, "Adenomatoid tumor of the tunica albuginea," International Journal of Urology, vol. 12, no. 5, pp. 516-518, 2005. 


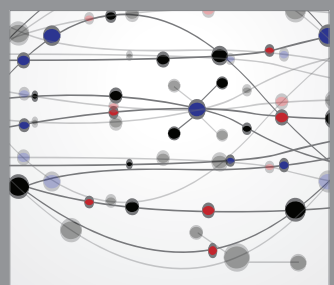

The Scientific World Journal
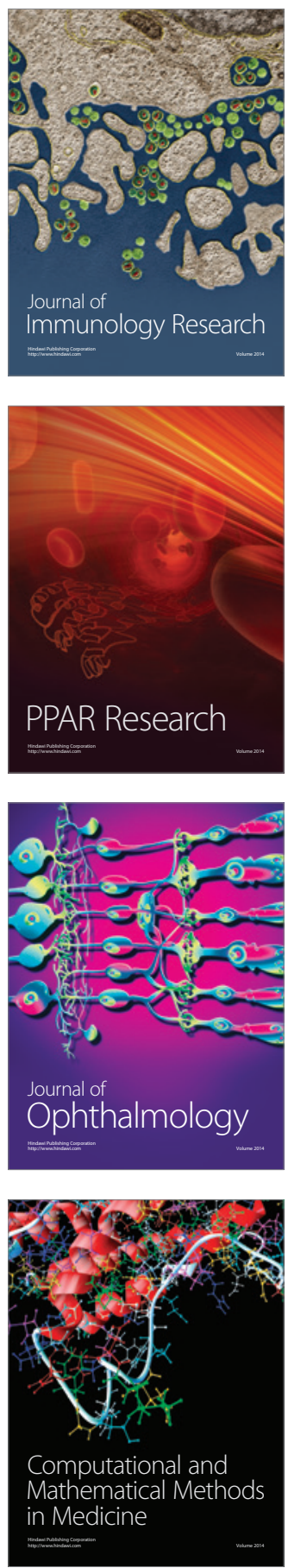

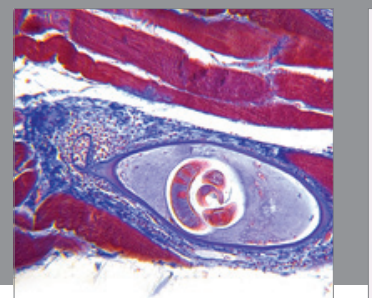

Gastroenterology

Research and Practice
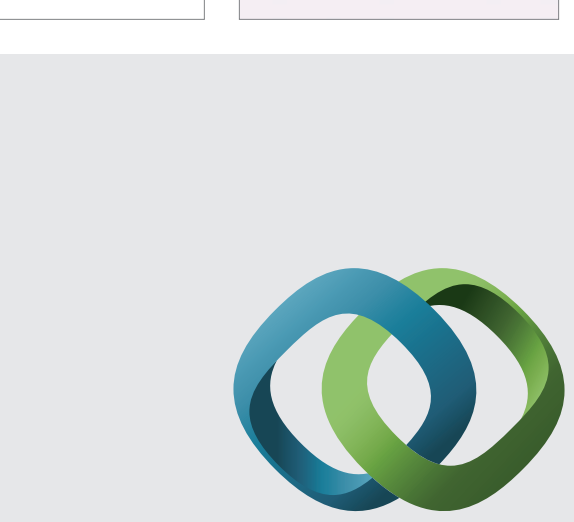

\section{Hindawi}

Submit your manuscripts at

http://www.hindawi.com
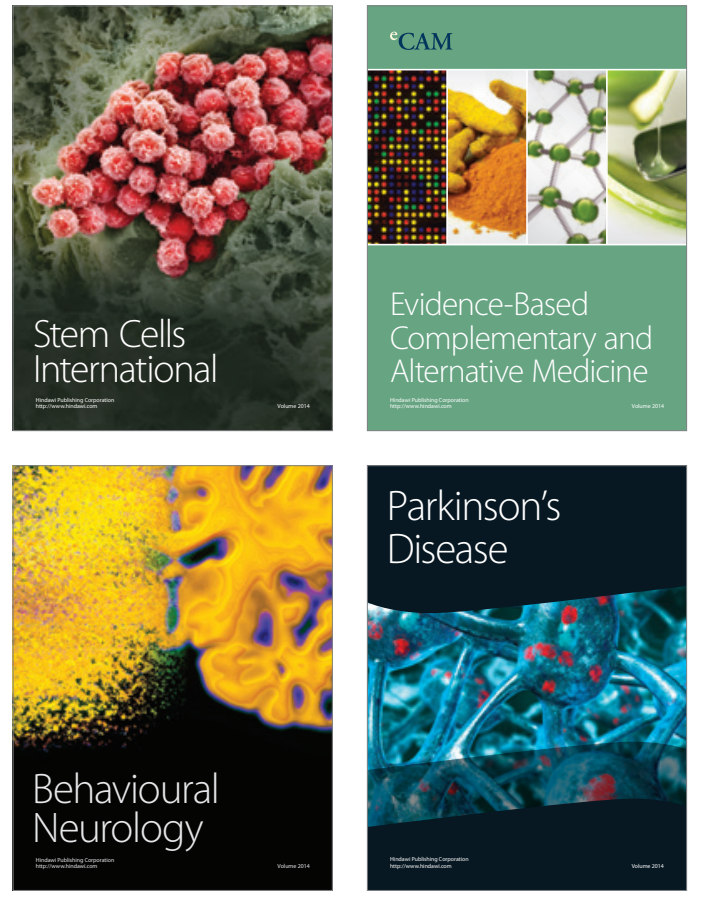
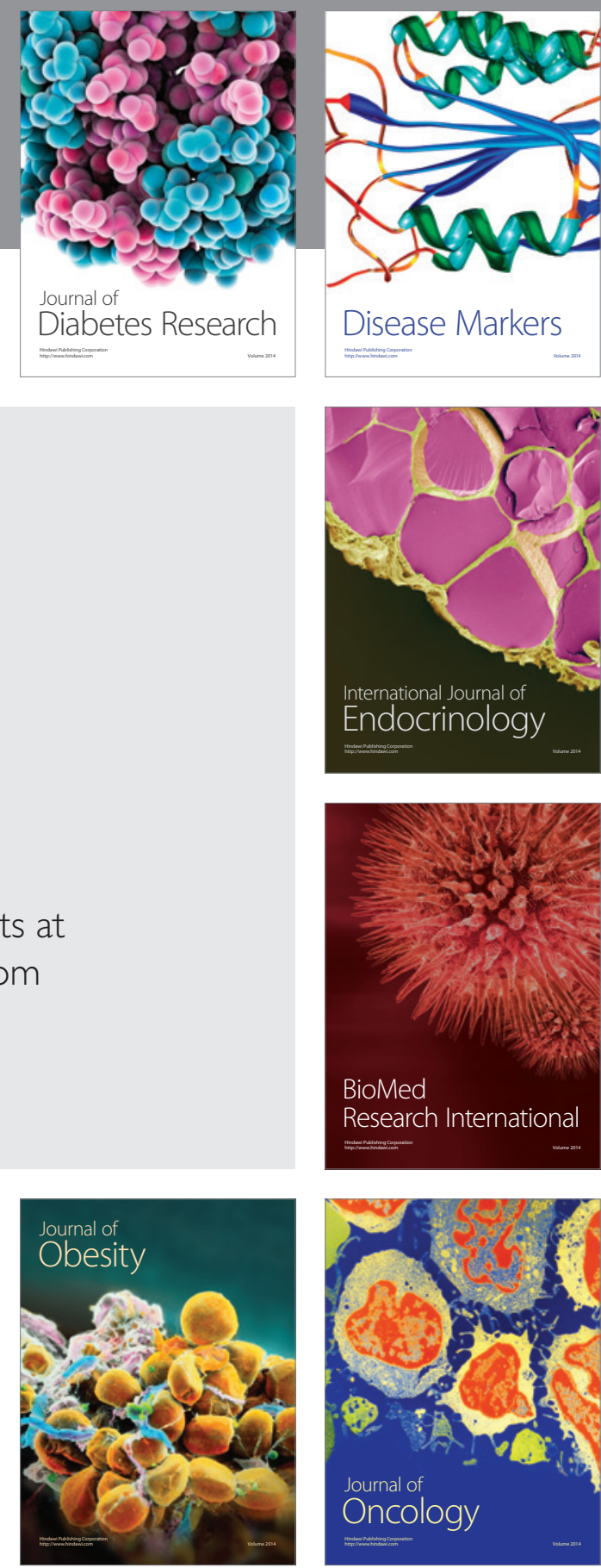

Disease Markers
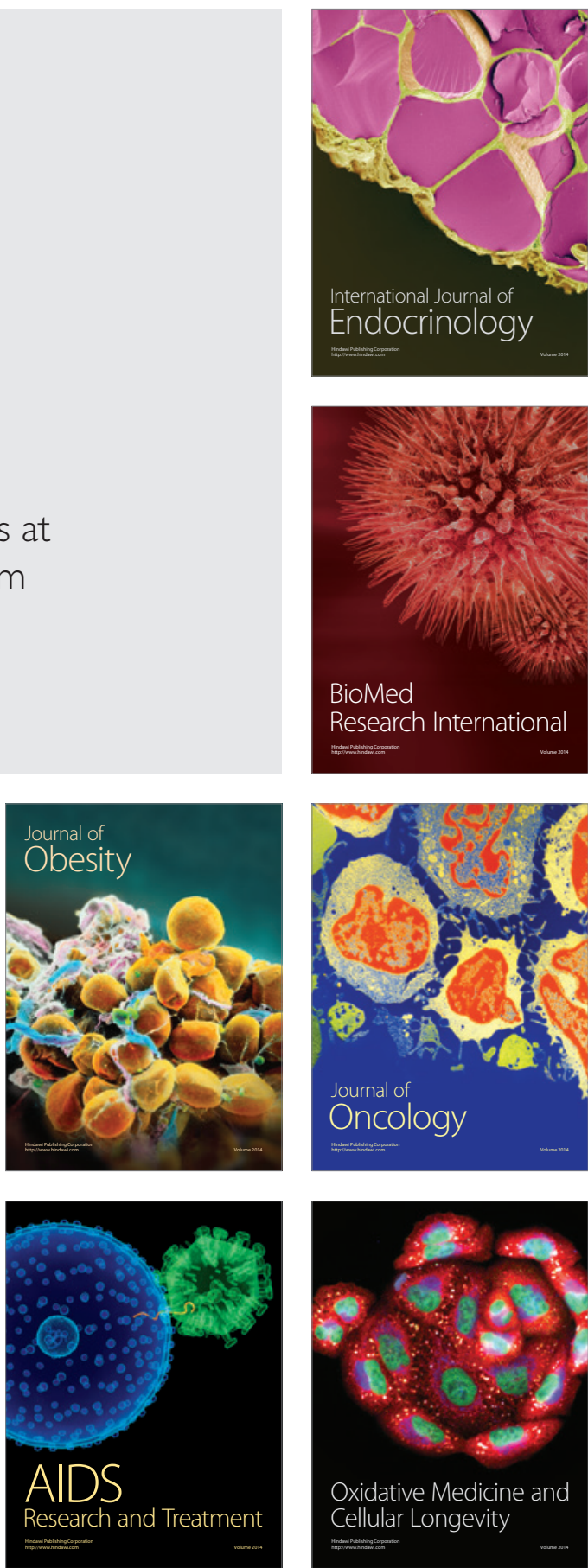